\title{
Results of the treatment with intravitreal bevacizumab injection in branch retinal vein occlusion
}

\section{Retinal ven dal tıkanıklığında intravitreal bevacizumab enjeksiyonu ile tedavi sonuçları}

\author{
Osman Sayın ${ }^{1}$, Nurullah Koçak ${ }^{2}$, Ebru Hamzaoglu ${ }^{3}$, Yüksel Süllü ${ }^{4}$ \\ ${ }^{1}$ Konya Beyhekim Devlet Hastanesi Göz Kliniği. Konya, Türkiye \\ ${ }^{2}$ Samsun Eğitim ve Araştırma Hastanesi Göz Kliniği, Samsun, Türkiye \\ ${ }^{3}$ Mersin devlet Hastanesi , Mersin, Türkiye \\ ${ }^{4}$ Ondokuz Mayıs Üniversitesi Tıp Fakültesi Göz Hastalıkları AD,Samsun, Türkiye
}

öz

Amaç: Retina ven dal tıkanıklığına sekonder maküla ödemi tedavisinde uygulanan intravitreal bevacizumab enjeksiyonun görme keskinliği ve maküla kalınlığı üzerine etkisini araştırmak.

Gereç ve Yöntem: Retina ven dal tıkanıklığına bağı maküler ödemi bulunan ve intravitreal bevacizumab enjeksiyonu uygulanan hastaların dosyaları retrospektif olarak incelendi. Hastaların enjeksiyon öncesi ve enjeksiyon sonrası takiplerindeki görme keskinliği (logMAR) ve tıkanıklığın bulunduğu kadrandaki maküler kalınlık değerleri kaydedilerek intravitreal bevacizumabın bu parametreler üzerindeki etkisi incelendi.

Bulgular: 17'si erkek, 7'si kadın toplam 24 hastanın 24 gözü

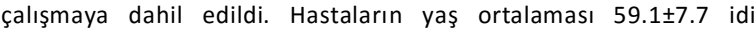
Enjeksiyon öncesi görme keskinliği ortalama $0.7 \pm 0.5 \log M A R$, maküler kalınlık değeri ortalama $489.7 \pm 129.6 \mu \mathrm{m}$ olarak tespit edildi. Uygulanan ortalama enjeksiyon sayısı $1.5 \pm 0.7$ idi. Enjeksiyon sonrası ortalama takip süresi $3.5 \pm 2.7$ aydı. 1 . Ayda görme keskinliğ $0.5 \pm 0.1 \log M A R$, maküla kalınlığı $393.1 \pm 5.7 \mu \mathrm{m}$ olarak tespit edildi. Hastaların son takiplerindeki görme keskinliği ortalama $0.26 \pm 0.28$ logMAR, maküler kalınlık değeri ortalama $317.4 \pm 71.5 \mu \mathrm{m}$ idi. Enjeksiyon sonucunda, ilk ve son kontroller arası görme keskinliğindeki artış ve maküla kalınlı̆ı̆ındaki azalma istatistiksel olarak anlamlı bulundu. $(\mathrm{p}<0.001)$.

Sonuç: Retina ven dal tıkanıklığına sekonder maküler ödemde uygulanan intravitreal bevacizumab enjeksiyonu görme keskinliğini arttırmakta ve maküler kalınlı̆ı̆ azaltmaktadır.

Anahtar Kelimeler: intravitreal bevacizumab, maküla ödemi, retinal ven tıkanıklığı

\section{ABSTRACT}

Objective: The aim was to study the effect of intravitreal bevacizumab injection (IVB), which is applied in macular edema treatment secondary to branch retinal vein occlusion (BRVO), on visual acuity and macular thickness.

Material and method: The files of patients who has macular edema caused by branch retinal vein occlusion and who were applied intravitreal bevacizumab injection were studied retrospectively. Visual acuity ( $\log M A R)$ in follow-ups of the patients before and after the injection and the macular thickness values of the quadrant of the occlusion were recorded and the effect of intravitreal bevacizumab on these parameters were analyzed.

Results: 24 eyes of 24 patients, 17 of which are male and 7 of which are female, were included in the study. The mean age of the patients were $59.1 \pm 7.7$. The mean visual acuity prior to the injection was determined to be $0.7 \pm 0.5 \log M A R$, and the mean macular thickness value $489.7 \pm 129.6 \mu \mathrm{m}$. The mean injection number applied was $1.5 \pm 0.7$. The mean follow-up time after the injection was $3.5 \pm 2.7$ months. The mean macular thickness was determined to be $393.1 \pm 5.7 \mu \mathrm{m}$ and mean visual acuity was $0.5 \pm 0.1 \log M A R$ in the $1 \mathrm{st}$ month. In the last follow-ups of the patients, the mean visual acuity was $0.26 \pm 0.28 \log$ MAR and the mean macular thickness value was $317.4 \pm 71.5 \mu \mathrm{m}$. The increase in visual acuity and the decrease between first and last control after the injection was found statistically significant $(\mathrm{p}<0.001)$.

Conclusion: The intravitreal bevacizumab injection used in macular edema secondary to BRVO increases visual acuity and decreases macular thickness.

Keywords: intravitreal injection, macular edema, retinal vein occlusion 


\section{GİRIŞ}

Retina ven tıkanıklığı, diyabetik retinopatiden sonra görme kaybına sebep olan en s1k ikinci retinal vasküler hastalıktır. T1kanıklığın tutulum bölgesine göre santral, hemisantral ya da dal tıkanıklı̆̆ 1 şeklinde ortaya çıkabilir. 40 yaş üstünde görülme sıklığı \%1-2 olarak bildirilmiştir.1-3 Retina ven dal tıkanıklığı (RVDT) daha sık izlenirken (\%0.61.1), santral retinal ven tıkanıklığ 1 daha nadir görülmektedir (\%0.1-0.4).4 Retina ven dal tıkanıklığında patoloji, arter ven çaprazlaşma bölgesinde arterin ven üzerinde yaptığı bası ile açıklanmaktadır. Bası sonucu oluşan türbülans ven duvarında endotel hasarına neden olmakta bu da tromboz ile sonuçlanmaktadır. Siklıkla alt ve üst temporal arkadlar tutulum gösterir ve venin trasesinde hemoraji ve eksudasyona neden olmaktadır.5,6

Retinal vasküler tıkanıklı sonucu çoğunlukla orta ya da ciddi görme kayıpları oluşmaktadır. Neden olduğu maküla ödemi görme kaybının en s1k nedeni olup olguların \%60'ında rapor edilmiştir.7 Kapiller endotel hücre harabiyeti, iskemik retinadan salınan vasküler endotelyal büyüme faktörü (VEGF) ve interlökin-6 (IL-6) gibi mediatörler maküler ödemle sonuçlanan kan retina bariyerinin bozulmasına neden olmaktadır.8 Günümüzde retinal vasküler tıkanıklığa sekonder maküla ödeminde; lazer fotokogülasyon,9 intravitreal deksametazon ve triamsinolon (IVTA) gibi steroidler,10,11 intravitreal bevacizumab12,13 (Avastin; Genentech Inc., South San Franscisco, Calif., USA) ve ranibizumab14,15 (Lucentis; Novartis Inc. Basel, Switzerland) gibi anti-VEGF ajanlar kullanılmaktadır. Bir monoklonal antikor olan bevacizumab'in RVDT'ye sekonder maküla ödeminde görme keskinliği ve maküla kalınlığı üzerine olan olumlu etkileri birçok çalışmada gösterilmiştir.16,17

Çalışmamızda, RVDT’ye bağlı maküla ödemi tedavisinde VEGF inhibitörü bevacizumab'in intravitreal enjeksiyonu sonras1 görme keskinliği ve anatomik sonuçların değerlendirilmesi amaçlandı.

\section{GEREÇ VE YÖNTEM}

Ondokuz Mayıs Üniversitesi Tıp Fakültesi Göz Hastalıkları Anabilim Dalı'nda çekilen fundus flurosein anjiografi (FFA) ve optik koherens tomografi (OKT) sonrasinda retina ven dal tıkanıklığına sekonder maküla ödemi tanis1 alan ve intravitreal bevaciumab (Avastin ${ }^{\circledR}$ ) tedavisi uygulanan 24 hastanın 24 gözü retrospektif olarak incelendi. Takibi 3 aydan kısa olan, iris/disk ve retinal neovaskülarizasyonu olan, epiretinal membranı olan, daha önce maküla ödemi nedeni ile intravitreal anti-VEGF, triamsinolon, deksametazon tedavisi veya lazer fotokoagülasyon uygulanan, diyabet veya başka bir sistemik hastalığı bulunan olgular çalışmaya dahil edilmedi. Maküla ödemi OKT ile ölçülen maküla kalınlığg $>250 \mu \mathrm{m}$ olmas1 olarak değerlendirildi.

Tüm hastalardan aydınlatılmış onam alındıktan sonra bevacizumab steril şartlarda $1.25 \mathrm{mg} / 0.05 \mathrm{ml}$ dozunda intravitreal olarak uyguland1. Enjeksiyon \%0.5 proparakain hidroklorür ve $\% 5^{\prime}$ lik povidon iodür damlatılmasını takiben $30 \mathrm{G}$ iğne kullanılarak limbusun 3-3.5 mm gerisinden alt temporal kadrandan yapıldı. Enjeksiyon sonras1 hastalara yedi gün süre ile kinolon grubu bir antibiyotik günde $5 \mathrm{kez}$ kullanılmak üzere verildi. İntravitreal tedavi PRN (pro re nata, gerektiğinde) protokolüne göre uygulandı. Bu protokolde enjeksiyon sonrasi mevcut bulguların devam etmesi veya daha kötüleşmesi görüldüğü takdirde enjeksiyona devam edildi. OKT'de maküla ödeminin (santral maküla kalınlığ $1>250 \mu \mathrm{m}$ ) eşlik ettiğ durumda, mevcut görme keskinliği 0.3 $\operatorname{logMAR}$ ya da altında tespit edilmişse intravitreal tedavi uygulandı. OKT'de maküla ödeminin devam etmesi ya da artması ve görme keskinliğinde azalma olması durumunda ise tedavi tekrarland1. Hastalar enjeksiyona bağlı komplikasyonlar açısından izlendi ve enjeksiyon sonrası aylı olarak kontrole 
çağırıldı. Enjeksiyon sonrası 1. ay ve son kontrolde hastaların en iyi görme keskinliği snellen eşeli ile ölçüldü ve ETDRS harf skorlamasına çevrildi. Bunun yanında her kontrolde biyomikroskop ile ön segment ve fundus muayenesi, goldmann aplanasyon tonometrisi ile göz içi basınçları, OKT ile maküla kalınlıkları değerlendirildi.

Tedavi öncesi ve sonrası görme keskinliği ve maküla kalınlıkları karşılaştırılmasında Wilcoxon testi kullanıldı. Toplanan verileri analiz için SPSS 15.0 programı kullanıldı ve $\mathrm{p}<0.05$ değeri istatistiksel olarak anlamlı kabul edildi.

\section{BULGULAR}

Çalışmaya RVDT tanısı konan en az 3 ay takip edilmiş 24 hastanın 24 gözü dahil edildi. Hastaların 17'si erkek (\%70.2) 7'si bayan (\%29.2) olup ortalama yaş 59.1 \pm 7.7 olarak tespit edildi (Tablo 1). Olguların tamamı enjeksiyonlar ve sonrasinda birer ay aralıklarla kontrollere çağırıldı ve OKT ile çekilen maküla filmlerinde ödemin devam etmesi ve/veya görme keskinliğinde azalma olması durumunda ilave enjeksiyon yapilması planlandı. Ortalama takip süresi 3.5 \pm 2.7 (3-10 ay) aydı. Ortalama 3.5 aylık izlem süresi boyunca 13 hastaya 1,10 hastaya 2 ve 1 hastaya dört enjeksiyon yapıldı. Ortalama enjeksiyon sayısı $1.5 \pm 0.7$ idi. Hastalara takip süresi içinde argon lazer fotokoagülasyon tedavisi uygulanmadi.

Son takipler incelendiğinde 24 hastanın 18'inde görme keskinliğinde $\geq 2$ sıra artış tespit edilirken 3 hastada $<2$ sıra artış tespit edildi. 1 hastada görme keskinliği değişmez iken 2 hastada birer sira kayıp görüldü. Son kontrolde maküla kalınlığı değerlendirildiğinde 24 hastanın 22'sinde maküla kalınlığında azalma olduğu görüldü. Sadece 2 hastanın maküla kalınlığında artış izlendi. Maküla kalınlığında artış olan hastaların birinde 1 sıra, diğerinde 2 sıra görme keskinliğinde artış gözlendi.
Enjeksiyon öncesi hastaların başlangıç görme keskinliği ortalama $0.7 \pm 0.5 \log \mathrm{MAR}$, santral maküler kalınlık değeri ortalama 489.7 $\pm 129.6 \mu \mathrm{m}$ olarak tespit edildi. Enjeksiyon sonras1 1. Ayda görme keskinliği $0.5 \pm 0.1 \log$ MAR, son kontrolde $0.26 \pm 0.28$ logMAR idi. Ortalama görme keskinliğinde tedavi öncesine kiyasla enjeksiyon sonrasi 1. ayda istatistiksel olarak anlamlı fark bulunmaz iken $(\mathrm{p}=0.074)$, son kontrolde fark anlaml olarak tespit edildi $(\mathrm{p}<0.001)$. Santral maküler kalınlık ortalaması enjeksiyon sonrası 1. ayda $393.1 \pm 5.7 \mu \mathrm{m}$, son kontrolde $317.4 \pm 71.5 \mu \mathrm{m}$ olarak saptandı. Santral maküla kalınlığında tedavi öncesi döneme göre tedavi sonrası 1 . ay ve son kontrolde istatistiksel olarak anlaml azalma tespit edildi (surasiyla $\mathrm{p}=0.021$, $\mathrm{p}<0.001$ ) (Tablo 2).

Tablo 1. Olguların epidemiyolojik özellikleri

\begin{tabular}{lc}
\hline Olguların özellikleri & \\
\hline Hasta/göz sayısı & $24 / 24$ \\
Ortalama yaş & $59.1 \pm 7.7$ \\
Kadın/erkek & $7 / 17$ \\
Ortalama izlem süresi(ay) & $3.5 \pm 2.7$ \\
Sağ göz/sol göz & $13 / 11$ \\
\hline
\end{tabular}

Tablo 2. Enjeksiyon öncesi ve sonrası kontrollerde görme keskinliği ve maküla kalınlık değerleri

\begin{tabular}{|c|c|c|c|c|c|}
\hline & $\begin{array}{l}\text { Tedavi } \\
\text { öncesi } \\
\end{array}$ & 1.ay & $\begin{array}{l}\mathbf{p} \\
\text { değeri }\end{array}$ & $\begin{array}{c}\text { Son } \\
\text { vizit }\end{array}$ & $\underset{\text { değeri }}{p}$ \\
\hline $\begin{array}{l}\text { Görme } \\
\text { (logMAR) }\end{array}$ & $0.7 \pm 0.5$ & $0.5 \pm 0.1$ & 0.074 & $0.26 \pm 0.28$ & $<0.001$ \\
\hline $\operatorname{SMK}(\mu \mathrm{m})$ & $489.7 \pm 129.6$ & $393.1 \pm 5.7$ & 0.021 & $317.4 \pm 71.5$ & $<0.001$ \\
\hline
\end{tabular}

SMK: santral maküler kalınlık

Hastalara yapılan 37 enjeksiyon sonucunda hiçbir hastada endoftalmi, retina dekolmanı gibi uygulamaya bağlı komplikasyonlar ya da bevacizumaba bağlı sistemik yan etki izlenmedi. 


\section{TARTIȘMA}

RVDT s1k görülen ve görmeyi tehdit eden bir hastalıktır. RVDT olan olguların bir kısmında maküla ödemi spontan olarak gerilerken diğer bir kısmında maküla ödemine bağlı görme kaybı hala önemli bir sorun olarak karşımızda durmaktadır. Günümüzde mevcut maküla ödemi tedavisinde kullanabileceğimiz etkinliği kanıtlanmış çeşitli alternatifler bulunmakla birlikte henüz kanıtlanmış altın standart bir tedavi bulunmamaktadır. Grid lazer fotokoagülasyon, intravitreal steroidler (IVTA, implant) ve intravitreal anti-VEGF ajanların birbirine üstünlükleri ve kombine kullanımları ile ilgili literatürde çok fazla sayıda çalışma bulunmaktadır.

Vasküler endotelyal growth faktörün anjiogenezdeki rolünün anlaşılması ve maküla dejeneresansında kullanım onayı almasından sonra RVDT, santral retinal ven oklüzyonu ve diyabetik maküler ödem gibi VEGF ile ilişkili diğer hastalıkların tedavisinde de kullanılmaya başlanmıştır. Bevacizumab VEGF'in tüm izoformlarına bağlanıp nötralize etme özelliğine sahip insanlaştırılmış monoklonal antikordur.18 Birçok çalışmada intravitreal bevacizumab enjeksiyonlarının RVDT olgularında maküla kalınlığında azalma ve görme keskinliğinde artış sağladığı gösterilmiştir.19,20 Göz için endikasyon dış1 olarak kullanılan intravitreal bevacizumab enjeksiyonunun kalp krizi, kanama, teratotoksisite, serebrovasküler olay, nefrotoksisite gibi sistemik komplikasyonları nadir de olsa görülmektedir.21

Uygulanan doz açısından RVDT olgularında tedavi amaciyla $1.25 \mathrm{mg}, 2.0 \mathrm{mg}$ ve $2.5 \mathrm{mg}$ gibi farklı dozlarda intravitreal uygulamalar yapılmış, iki yıl sonunda maküla kalınlığg ve görme keskinliği açısından anlamlı fark bulunmamıştır.22 Pai ve ark. Santral retinal ven ve retinal dal tıkanıklığına bağlı maküla ödemi olan hastalara intravitreal 1.25 $\mathrm{mg}$ bevacizumab tedavisi uygulamış, 3. Ayda görme keskinliğinde anlamlı artış ve maküla kalınlığında azalma tespit etmişlerdir.23
Rabena ve ark. ise RVDT'si olan 27 hastalık olgu grubunda intravitreal bevacizumab uygulamış, ortalama 5.3 hafta sonunda maküla kalınlığında azalma ve görme keskinliğinde anlamlı artış tespit etmiştir.17 Biz de çalışmamızda literatüre benzer şekilde 1 . ay ve 3. ay sonunda başlangıca göre görme keskinliğinde artış ve maküla kalınlığında azalma gözledik.

RVDT' de en yaygin kullanılan intravitreal bevacizumab protokolü ilk 5-6 aylık süreçte 23 enjeksiyon şeklindedir.24 İlaç etkinliğinin non-vitrektomize gözlerde ortalama 6-8 hafta sürdügü ve intravitreal yarılanma ömrünün 9.82 gün olduğu bildirilmiştir. 25 Rabena ve ark.' 'ları çalışmalarında RVDT olgularına ortalama 2 enjeksiyon, ülkemizden Küsbeci ve ark.26 ortalama 2.3 enjeksiyon uygulayarak stabilizasyon sağlamışlardır. Çalışmamızda ortalama 3.5 aylık takip sürecinde olgularımıza ortalama 1.5 intravitreal enjeksiyon uygulandi. Çalışmamızın eksik yönlerinden biri tüm olgular için sabit bir son kontrol noktasının bulunmaması ve takip süresinin kısalığıdır ve bu durum nihai enjeksiyon sayısinı etkilemektedir.

Enjeksiyon endikasyonu PRN protokolüne göre uyguland. Ito ve ark.27 ilk dozun ardından PRN protokolü uygulanan hastalar ile 3 doz yükleme yapılan ve ardından PRN'ye geçilen olgular arasında 12 ay sonunda maküla kalınlığı ve görme keskinliği açısından fark olmadığını bildirmiştir. Bunun yanında aynı çalışmada daha az enjeksiyonun endoftalmi ve enjeksiyona sekonder komplikasyonları da azaltabileceği vurgulanmıştır. Biz de çalışmamızda ilk enjeksiyonun ardından gerektiğinde enjeksiyon yapmayı tercih ettik.

Görme keskinliği ve maküla kalınlığ arasındaki ilişki incelendiğinde 2 olguda maküla kalınlığında artış olurken görme keskinliğinde de artış izlenmesi, maküla kalınlığında azalma olan 2 olguda ise görme düzeyinde azalma olması daha önceki çalışmalar ile benzer şekilde maküla kalınlığ ile görme düzeyi arasinda korelasyon 
olmadığını göstermektedir. Santral makülar kalınlık azalırken görme düzeyinin artmadığ 2 olguda en dikkat çekici nokta FFA'da tespit edilen foveal avasküler zondaki (FAZ) bozulmadır. Rouvas ve ark. çalışmalarında FAZ'da bozulma olan hastalarda görme artışının sağlanamadığını bildirmişlerdir.28

Çalışmaya dahil edilen hiçbir hastada katarakt, sekonder glokom, enflamasyon, endoftalmi, retina yırtığı, retina dekolmanı, vitreus kanaması gibi ciddi göz komplikasyonları veya sistemik bir yan etki izlenmedi.

\section{SONUÇ}

RVDT'ye bağlı maküla ödemi tedavisinde intravitreal bevacizumabın etkinliği kanıtlanmış olmakla birlikte halen cevaplanmayı bekleyen sorular bulunmaktadır. Anatomik ve fonksiyonel düzelmenin sürekliliğinin sağlanması için daha uzun süreli çalışmalara ihtiyaç duyulmaktadır.

\section{KAYNAKLAR}

1. Mitchell P, Smith W, Chang A. Prevalence and associations of retinal vein occlusion in Australia: the Blue Mountains Eye Study. Arch Ophthalmol 1996;114:1243-7.

2. Klein R, Klein BE, Moss SE et al. The epidemiology of retinal vein occlusion: the Beaver Dam Eye Study. Trans Am Ophthalmol Soc 2000;98:133-41.

3. Wong TY, Scott IU. Clinical practice. Retinal-vein occlusion. N Engl J Med 2010;363:2135-44.

4. David R, Zangwill L, Badarna $M$ et al. Epidemiology of retinal vein occlusion and its association with glaucoma and increased intraocular pressure. Ophthalmologica. 1988; 197:69-74.

5. Zhao J, Sastry SM, Sperduto RT et al. Arteriovenous crossing patterns in branch retinal vein occlusion. Ophthalmology. 1993;100:423-428.

6. Christoffersen NL, Larsen M. Pathophysiology and hemodynamics of branch retinal vein occlusion. Ophthalmology. 1999;106:2054-62.

7. Greer DV, Constable IJ, Cooper RL. Macular edema and retinal branch vein occlusion.
Aust J Ophthalmol. 1980;8:207-209.

8.Noma $\mathrm{H}$, Minamoto A, Funatsu $\mathrm{H}$ et al. Intravitreal levels of vascular endothelial growth factor and interleukin- 6 are correlated with macular edema in branch retinal vein occlusion. Graefes Arch Clin Exp Ophthalmol 2006;244:309-15.

9. SCORE Study Research Group. A randomized trial comparing theefficacy and safety of intravitreal triamcinolone with standard careto treat vision loss associated with macular edema secondary tobranch retinal vein occlusion: the Standard Care vs Corticosteroidfor Retinal Vein Occlusion (SCORE) Study report 6. Arch Ophthalmol 2009;127:1115-28.

10. Haller J, Bandello F, Belfort R Jr et al. OZURDEX GENEVA Study Group. Randomized, sham-controlled trial of dexamethasone intravitreal implant in patients with macular edema due to retinal vein occlusion. Ophthalmology 2010;117:1134-46.

11. Özdek S, Tiftikçioğlu Y, Gürelik G et al. Posterior subtenon triamcinolone, intravitreal triamcinolone and grid laser photocoagulation for the treatment of macular edema in branch retinal vein occlusion. Ophthalmic Res 2008;40:26-31.

12. Ahmadi AA, Chuo JY, Banashkevich A et al. The effects of intravitreal bevacizumab on patients with macular edema secondary to branch retinal vein occlusion. Can J Ophthalmol 2009;44:154-9.

13. Prager F, Michels S, Kriechbaum K et al. Intravitreal bevacizumab (Avastin) for macular edema secondary to retinal vein occlusion: 12month results of prospective clinical trial. $\mathrm{Br} \mathrm{J}$ Ophthalmol 2009;93:452-6.

14. Campochiaro PA, Heier JS, Feiner L et al. BRAVO Investigators. Ranibizumab for macular edema following branch retinal vein occlusion:sixmonth primary end point results of a phase III study. Ophthalmology 2010;117:1102-12.

15. Brown DM, Campochiaro PA, Singh RP et al. CRUISE Investigators. Ranibizumab for macular edema following central retinal vein occlusion:six-month primary end point results of a phase III study. Ophthalmology 2010;117:1124 -33.

16. Spandau U, Wickenhauser A, Rensch F et al. Intravitreal bevacizumab for branch retinal vein occlusion. Acta Ophthalmol Scand 2007;85:118-9.

17. Rabena MD, Pieramici DJ, Castellarin AA et al. Intravitreal bevacizumab (Avastin) in the treatment of macular edema secondary to branch retinal vein occlusion. Retina 2007;27:419-25. 
18. Ferrara N, Hillan KJ, Novotny W. Bevacizumab (Avastin), a humanized anti-VEGF monoclonal antibody for cancer therapy. Biochem Biophys Res Commun. 2005;333:328-335.

19. Gunduz K, Bakri SJ. Intravitreal bevacizumab for macular edema secondary to branch retinal vein occlusion. Eye (Lond). 2008;22(9):1168-1171

20.Moradian S, Faghih H, Sadeghi B et al. Intravitreal bevacizumab vs sham treatment in acute branch retinal vein occlusion with macular edema: Results at 3 months. Graefes Arch Clin Exp Opthalmol. 2011;249:193-200.

21. İnan ÜÜ. Anti-VEGF ajanlarda toksisiteyan etkiler. Ret-Vit. 2007;15 Özel Sayı:55-62

22. $\mathrm{Wu} \mathrm{L}$, Arevalo JF, Berrocal $\mathrm{MH}$ et al. Comparison of two doses of intravitreal bevacizumab as primary treatment for macular edema secondary to branch retinal vein occlusions: results of the Pan American Collaborative Retina Study Group at 24 months. Retina. 2009;29:13961403.

23. Pai AS, ShettyR, Vijayan PB et al. Clinical, Anatomic and Electrophysiologic Evaluation Following Intravitreal Bevacizumab for Macular Edema in Retinal Vein Occlusion. Am J Ophthalmol.2007; 143:601-606.

24. Badala F. The treatment of branch retinal vein occlusion with bevacizumab. Curr Opin Ophthalmol. 2008;19:234-238.

25. Krohne TU, Eter N, Holz FG et al. Intraocular Pharmacokinetics of Bevacizumab. After a Single Intravitreal Injection in Humans. Am J Ophthalmol. 2008;146:508-512.

26. Küsbeci T, İnan ÜÜ, Yavaş G et al. Retina ven dal tıkanıklığına bağlı maküla ödeminde intravitreal bevacizumab (Avastin) enjeksiyonunun uzun dönem sonuçları. Ret-Vit. 2009;17:88-92

27. Ito Y, Saishin Y, Sawada O et al. Comparison of single injection and three monthly injections of intravitreal bevacizumab for macular edema associated with branch retinal vein occlusion. Clinical Ophthalmology. 2015:9:175180

28. Rouvas A, Petrou P, Ntouraki A et al. Intravitreal ranibizumab (Lucentis) for branch retinal vein occlusion-induced macular edema: nine-month results of a prospective study. Retina 2010;30:893-902. 